\title{
Risk Attitude towards Pandemic Threat - Covid 19 among Millennials in Malaysia
}

Noraznira Abd Razak, Wan Norhayate Wan Daud, Najihah Hanisah Marmaya, Nur Melissa Muhammad Faisal Wee, Mohd Zaki Sadik, Hafiza Harun

To Link this Article: http://dx.doi.org/10.6007/IJARBSS/v11-i11/11617

DOI:10.6007/IJARBSS/v11-i11/11617

Received: 23 September 2021, Revised: 26 October 2021, Accepted: 08 October 2021

Published Online: 17 November 2021

In-Text Citation: (Razak et al., 2021)

To Cite this Article: Razak, N. A., Daud, W. N. W., Marmaya, N. H., Wee, N. M. M. F., Sadik, M. Z., \& Harun, H. (2021). Risk Attitude towards Pandemic Threat - Covid 19 among Millennials in Malaysia. International Journal of Academic Research in Business and Social Sciences, 11(11), 1425 - 1432.

Copyright: (c) 2021 The Author(s)

Published by Human Resource Management Academic Research Society (www.hrmars.com) This article is published under the Creative Commons Attribution (CC BY 4.0) license. Anyone may reproduce, distribute, translate and create derivative works of this article (for both commercial and non0-commercial purposes), subject to full attribution to the original publication and authors. The full terms of this license may be seen at: http://creativecommons.org/licences/by/4.0/legalcode

Vol. 11, No. 11, 2021, Pg. 1425 - 1432

Full Terms \& Conditions of access and use can be found at http://hrmars.com/index.php/pages/detail/publication-ethics 


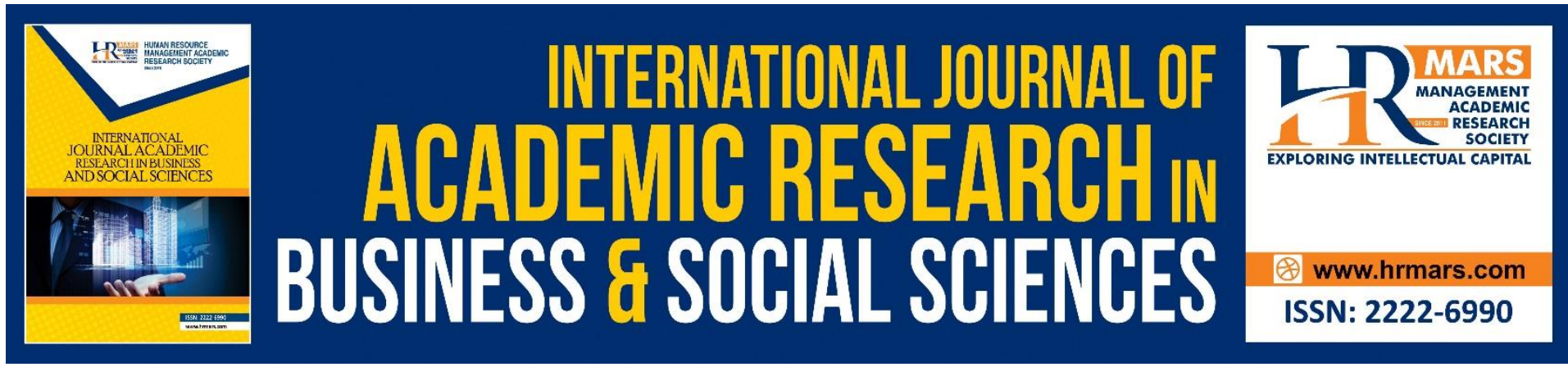

\title{
Risk Attitude towards Pandemic Threat - Covid 19 among Millennials in Malaysia
}

\author{
Noraznira Abd Razak, Wan Norhayate Wan Daud, Najihah \\ Hanisah Marmaya, Nur Melissa Muhammad Faisal Wee, Mohd \\ Zaki Sadik, Hafiza Harun \\ University Technology MARA Melaka, Malaysia, University Sultan Zainal Abidin
}

Email: noraznira@uitm.edu.my

\begin{abstract}
The study is conducted to investigate the extent of risk attitude towards pandemic threat among millennials in Malaysia its the relationship that involves variables partially adopted from protection motivation theory (PMT) such as perceived severity and response efficacy towards risk attitude among millennials during our current global pandemic covid 19 . The purpose of this research is to investigate the risk attitude among millennials as part of the crucial element in the adaptive risk attitude or behavior towards Covid 19. It is important to see the pattern of various behavioural element among millennials as it is not only associated with their opportunities, capacities, aspirations, energy and creativity as current and future human capital for Malaysia but also how they adapt themselves in order to deals with uncertain pandemic risks that happen in current times to enable the survival instinct to be ready at all cost. This study applies analysis technique using SmartPLS 3.4 version involved 197 respondent among millennials of various race in Malaysia. This study partially adopted Protection Motivation Theory (PMT) as main underlying framework to further explained the variables involved.
\end{abstract}

Keywords: Risk Attitude, Pandemic Threat, Behaviour, Perceived Severity, Response Efficacy

\section{Introduction}

The evolving global health system should be an enablers that protect and promote human health whilst the world continues to be confronted by longstanding, emerging, and reemerging infectious disease threats (Bloom \& Cadarette, 2019). These continuous emerging threats differs in terms of its severity however, the aftermath and emergence and reemerging of the pandemic threat with different dynamic arrays such as Ebola, Zika, dengue, Middle East respiratory syndrome, severe acute respiratory syndrome, and influenza like continues to take turns. As of 22 September 2021, the ongoing COVID-19 pandemic has so far claimed over 24,412 lives to date in accordance to Ministry of Health web page on Covid 19. During the early phase of COVID-19 worldwide spread, even before the first reported case in Malaysia, the $\mathrm{MOH}$ has come up with a comprehensive preparedness plan. This plan encompassed several key components including enhanced screening and interagency collaborations at entry points (airports, seaports etc); bolster sampling at health clinics and hospitals; 
designation of hospitals and laboratories nationwide as "treating" and "sampling" centers, respectively, empowering the public health surveillance system through active case detection and robust contact tracing. How human nature response towards these various mitigation risk plan to overcome these nature of risks would be ambiguous, the fear and panic with respect to this pandemic threat of Covid 19 has to be magnified as various perspective towards this current pandemic risk shall lead to economic risks and social risks as well our country's economic growth as it almost shaken up all types of businesses on a massive scale (Hasanat et al., 2020). It is notable that the economics downturn shall also reflects on social and psychological risk as well psychological state of people, mainly fear and anxiety. In short, these risks will affects the cycle of survival among the people at every level especially our future human capitals namely millennials. Therefore, this study is to investigate the risk attitude towards pandemic risk such as Covid 19 among millennials in Malaysia by partially adopting Protection Motivation Theory (PMT) as main underlying framework.

\section{Protection Motivation Theory (PMT)}

Protection Motivation Theory (PMT) is a major health psychology theory aimed at explaining the cognitive process of behavioural change in terms of threat and coping appraisal (Razak et al., 2018). The protection motivation theory (PMT) is an established theory, originally developed to explain how to influence risky behaviour and which components influence the persuasive message that reach out to the behaviour of an individuals. The PMT builds on the theory of fear appeals and at its core lies the idea that the behaviour of individuals is influenced by their threat appraisal (how thrilling, severe and likely an unwanted consequence is) and their coping appraisal (how efficient, manageable and costly the risk reducing behaviour is)(Rogers, 1983).

According to Plotnikoff et al (2009), the PMT stipulates that the emotional state of fear arousal influences attitudes and behaviour change indirectly through the appraisal of the severity of the danger. The model's coping appraisal consists of the individual's expectancy that carrying out recommendations can remove the threat (response efficacy) and belief in one's capability to execute the recommended course of action successfully (Plotnikoff et al., 2009). This theory has been widely adopted as crucial framework for the prediction and intervention in health-related behaviour which in sync with the core issue of this study hence the general purpose of this study is to analyze the relationship between perceived severity and response efficacy among others towards adaptive risk attitude among millennials during pandemic threat such as Covid 19.

\section{- Adaptive Risk Attitude towards Pandemic Threat Covid 19}

McMath \& Prentice-Dunn, (2005) found that even when individuals are confronted with accurate and applicable information regarding their health, predicting their behavior is often not straightforward. Much of this literature suggests that at times people defensively resist highly relevant messages. Risk attitudes are people's intentions to evaluate a risk situation in a favorable or unfavorable way and to act accordingly. It is very important to study and tapping the accuracy of the repercussions of certain policy to be implemented towards public generally as the effectiveness of the policy or strategies would be measured by how the response would be. According to Razak et al., (2018) attitude will change based on not only the level of fear induced by the event but also as a function of a person's actual ability to cope and the social norms and values with the risk that they face. The greater the perceived threat, the individual shall be motivated to protect themselves and eventually lead to protectiveness 
attitude. On the other hand, the so call underlying traits of cautiousness are also synonym with another risk terminology such as risk propensity and risk aversion (Rohrmann, 2008). Individual risk attitude or "the level to which individuals cope with, respond to, and or support changes that affect their roles as individuals has direct consequences on the way the act towards specific risk. The unknown and persistent worrying leads to an avoidance reaction and dependence on alternative method of medical practices (Vijayaraghavan \& SinghalL, 2020). During Covid-19 outbreak, the information overflow through social media including misinformation has heighted public mental health crisis (Dong et al., 2020). Unwarranted rumors or sensational media coverage has the capability to build misconception, misinformation regarding threat estimate in the minds of general public especially millennials whose undeniably stands as major cruxes in the total number of social media user nowadays (WHO, 2020 n.d). It is very important to know the part and parcel of layered level of attitude among them as they formed a large number of percentage in the community as a whole. How to handle various emerging risks in the future and how to act accordingly towards reducing healthy risk in such situation would be necessary towards the sustainability and resiliency of the respective community specifically and respective countries generally.

\section{- Perceived Severity}

According to PMT, protection motivation arises from the following two aspects: threat appraisal and coping appraisal (Rogers, 1975). Threat appraisal involves one's assessment of the risk degree of adverse consequences posed by a threatening event or unsafe behaviours (Rogers, 1975; Workman et al., 2008). It consists of perceived severity as one of the two items which represents the severity of the consequences of anticipated threats. In this study, perceived severity is taken to measure the severity of threats caused by unreservedly sharing knowledge of pandemic Covid 19. Perceived severity show how the individual believes and act in seriousness towards the threat would impact be to his or her own life (Milne et al., 2006). Thus, perceived severity is considered very crucial predictor underlying the basis of this study as it critically relates to how individual manage their level of inner fear and reflect attitude towards pandemic risk environment such as Covid 19.

Second components under PMT is coping appraisal which involves the evaluation of one's capacity to deal with and avoid a threatening event (Lee, 2011; Rogers, 1975). It consists of three sub-constituents whereby one of the dimensions be known as response efficacy.

\section{- Response Efficacy}

Response efficacy is as often as possible conceptualized as a faith in the capacity of a prescribed conduct to reduce a risk. Response efficacy alludes to a man's conviction in the matter of whether suggest activity step will really keep away from risk. Response efficacy is likewise characterized as the degree individuals trust a suggested reaction adequately dissuades or lightens a wellbeing risk (McMath \& Prentice-Dunn, 2005). Response efficacy is related to one's belief about the perceived benefits of a coping behavior. Here, it is taken to be the effectiveness of withholding knowledge of Covid 19 to avert a threat. Its incorporate an attitudinal part (result hopes) of the outcomes individuals suspect when they participate in a particular wellbeing conducts. Response efficacy is worried with whether an endorsed cure or strategy can deliver a specific wellbeing related objective. Nowadays, within Malaysia environment, the response efficacy while Malaysian is still within the restrict movement order (RMO) time frame and the response when it is already in the recovery phase differs greatly which rooted from the perceived response efficacy norm towards the level of the risk that 
they faced which shows that the perceived nature of this variables nonetheless highly correlates. Thus, two hypotheses has been established for this research from the research framework:

H1: There is a positive relationship between perceived severity and risk attitude towards Covid 19

H2: There is a positive relationship between response efficacy and risk attitude towards Covid 19

\section{Methodology}

This study adopted a quantitative approach and data were gathered via survey using selfadministered questionnaire. The study population for this research originated from a sample of 600 respondents which already categorize as millennial who had the birth years ranging from 1981 to 1996 respectively. The response rate stands at $32.8 \%$ which is within acceptable range.

\section{Results and Discussion}

The demographic results showed that more than half of the sample, 80.8 percent were from female respondents and 58.6 percent of those respondents comes from the age 21-30 years old. The demographic data of the respondents showed that all of the respondents come from the diverse educational background. More than 74 percent of the respondents comprised of diploma holder and the rest comes from undergraduates and postgraduates level.

\section{Assessment on Reflective Measurement Model}

All item loadings stands equal and more than 0.70 whilst AVE of all average variance extracted (AVE) and $C R$ values stands greater than 0.50 and 0.7 respectively, suggesting convergent validity of the model has satisfactory internal consistency reliability when the composite reliability $(C R)$ of each construct exceeds the threshold value of 0.7 . All CR values that are greater than 0.70 indicate an acceptable reliability. Thus, the results indicate that the items used to represent the constructs have satisfactory internal consistency reliability.

Table 1: Fornell-Larcker Criterion

$\begin{array}{llll} & \begin{array}{l}\text { perceived } \\ \text { severity }\end{array} & \text { response efficacy } & \text { risk attitude } \\ \text { perceived severity } & \mathbf{0 . 7 2 5} & & \\ \text { response efficacy } & 0.185 & \mathbf{0 . 8 3 1} & \\ \text { risk attitude } & 0.169 & 0.290 & \mathbf{0 . 7 3 6}\end{array}$

Based on Table 1, an off-diagonal elements are lower than square roots of AVE (bolded on the diagonal). Hence, the result indicating an adequate discriminant validity for all of the reflective constructs. As for table 2, the HTMT criterion also indicates that the confidence interval does not show the value of 1 on any of the construct which also confirms discriminant validity. 
Table 2: Heterotrait-Monotrait Ratio (HTMT)

$\begin{array}{llll} & \begin{array}{l}\text { perceived } \\ \text { severity }\end{array} & \text { response efficacy } & \text { risk attitude } \\ \begin{array}{l}\text { perceived severity } \\ \text { response efficacy }\end{array} & 0.300 & \\ \text { risk attitude } & 0.236 & 0.366\end{array}$

\section{Assessment of Structural Model}

Two direct hypotheses are developed between the constructs. T- statistics for all paths are generated via SmartPLS3.4 bootstrapping analysis. One of the two are found to have t-value $\geq 1.645$, thus significant at 0.05 level namely response efficacy construct is positively related to risk attitude towards pandemic covid 19 with $(\beta=0.268, p<0.01)$. On the other hand, perceived severity are not positively related on risk attitude construct by $\beta=0.119, p>0.01$ ). Thus, $\mathrm{H} 1$ is accepted and $\mathrm{H} 2$ is not accepted.

(Henseler et al., 2009) indicates that moderate or average $\mathrm{R}^{2}$ values are acceptable when the endogenous construct is explained by few exogenous construct. For this research, perceived severity and response efficacy explained $9.83 \%$ of the variance in risk attitude with $R^{2}=0.098$, which is considered small. The $\mathrm{f}^{2}$ value of 0.07 indicates response efficacy have a small effect in producing the $R^{2}$ for risk attitude. The $f^{2}$ value of 0.015 indicates perceived severity also has small effect in producing the $R^{2}$ for risk attitude. The predictive relevance $\left(Q^{2}\right)$ of risk attitude has a value of greater than 0 which stands at 0.032, which indicates that the model has a small predictive relevance for the endogenous constructs namely risk attitude (Sarstedt et al., 2014)

Table 3 Path coefficients, Observed t-statistics and results for all hypothesized path

\begin{tabular}{|c|c|c|c|}
\hline & Path Coefficient & $\begin{array}{l}T \quad \text { Statistics } \\
(|O / S T D E V|)\end{array}$ & Results \\
\hline $\begin{array}{l}\text { perceived severity }->\text { risk } \\
\text { attitude }\end{array}$ & 0.119 & 0.890 & $\begin{array}{l}\text { Not } \\
\text { supported }\end{array}$ \\
\hline $\begin{array}{l}\text { response efficacy } \rightarrow>\text { risk } \\
\text { attitude }\end{array}$ & 0.268 & 2.984 & Supported \\
\hline
\end{tabular}

Note: $*$ t-values $>1.645(p<0.05) ; * *$ t-values $>2.33(p<0.01)$ (one-tailed test)

Results from the study indicate that response efficacy are one of the significant predictors in explaining the risk attitudes of the millennials towards the pandemic Covid 19 in Malaysia. This finding supports the argument Milne et al (2006) on the significant impact of response efficacy towards endogenous construct established in PMT theory. The lower value of R2 in explaining the risk attitude construct may be due to various predictors that already established as part of predictors in PMT framework such as self efficacy, perceived vulnerability among others that should be included but absence in this study. It is suggested to includes other related construct already established under the basis of PMT theory in the future research. As for the significant and positive finding of response efficacy construct towards risk attitude, this is also in line with the finding of Reynaud et al (2013) and Yıldırım et al (2020) due to the core element of response efficacy itself is the belief and trust on the effectiveness of recommended protective steps taken based on the risky environment that they involves in, however the nature of the response efficacy itself is going to differ from one individual to another. The feedback will not be the same let alone the convincing perception 
on the effectiveness towards certain things namely related issues on pandemic such as vaccination risks etc. It is up to own personality and its perspective to react in certain mannerism towards various issues that relates to the risks that emerge from time to time especially with the scale of risks as massive as what we have nowadays.

\section{Conclusion}

Results of the study suggest that both predictor namely perceived severity and response efficacy might yield contradictory results due to the different nature of each construct in PMT. This might originate from individual preferences as that is the basic nature of human being. The mediation or moderation element relationship might also exists within the same framework and it is going to be fruitful if further probing on the relationship between variables and future variables become possible in the future research of same setting. There are also possibilities that other variables that are not included together in this study also have an impact on the endogenous construct. As for this research, future studies should continuously testing the core propositions of the other dimension in PMT in an attempt to suggest another fruitful multidisciplinary avenue by including risk behaviour interactions, combinations, and regroup with other element within the PMT and research setting itself.

\section{References}

Bloom, D. E., \& Cadarette, D. (2019). Infectious disease threats in the twenty-first century: Strengthening the global response. Frontiers in Immunology, 10(MAR), 1-12. https://doi.org/10.3389/fimmu.2019.00549

Dong, Y., Dong, Y., Mo, X., Hu, Y., Qi, X., Jiang, F., Jiang, Z., Jiang, Z., Tong, S., Tong, S., \& Tong, S. (2020). Epidemiology of COVID-19 among children in China. Pediatrics, 145(6). https://doi.org/10.1542/peds.2020-0702

Hasanat, M. W., Hoque, A., Shikha, F. A., Anwar, M., Abdul Hamid, A. B., \& Hon Tat, H. (2020). The Impact of Coronavirus (Covid-19) on E-Business in Malaysia. Asian Journal of Multidisciplinary Studies, 3(1), 85-90.

https://searchdisasterrecovery.techtarget.com/The-impact-of-coronavirus-onbusiness-continuity-planning?track=NL-

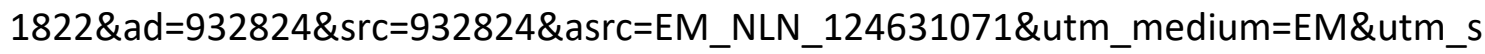
ource=NLN\&utm_campaign $=20200310$ Is your business continuity plan

Henseler, J., Ringle, C. M., \& Sinkovics, R. R. (2009). The Use of Partial Least Squares Path Modelling in International Marketing. Advances in International Marketing, 20(1), 277319. https://doi.org/10.1108/S1474-7979(2009)0000020014

McMath, B. F., \& Prentice-Dunn, S. (2005). Protection motivation theory and skin cancer risk: The role of individual differences in responses to persuasive appeals. Journal of Applied Social Psychology, 35(3), 621-643. https://doi.org/10.1111/j.1559-1816.2005.tb02138.x

Milne, S., Sheeran, P., \& Orbell, S. (2006). Prediction and Intervention in Health Related Behavior: A Meta Analytic Review of Protection Motivation Theory. Journal of Applied Social Psychology, 30(1), 106-143. https://doi.org/10.1111/j.1559-1816.2000.tb02308.x

Plotnikoff, R. C., Rhodes, R. E., \& Trinh, L. (2009). Protection motivation theory and physical activity: A longitudinal test among a representative population sample of canadian adults. Journal of Health Psychology, 14(8), 1119-1134.

https://doi.org/10.1177/1359105309342301

Razak, N. A., Marmaya, N. H., Karim, R. A., Wee, N. M. B. M. F., \& Ridzuan, A. R. bin. (2018). Adaptive Behavior towards Work Environment among Internship Students. International 
Journal of Academic Research in Business and Social Sciences, 8(11), 130-137. https://doi.org/10.6007/ijarbss/v8-i11/4889

Reynaud, A., Aubert, C., \& Nguyen, M. H. (2013). Living with floods: Protective behaviours and risk perception of vietnamese households. Geneva Papers on Risk and Insurance: Issues and Practice, 38(3), 547-579. https://doi.org/10.1057/gpp.2013.16

Rogers, W. R. (1983). Cognitive and physiological processes in fear appeals and attitude change: a revised theory of protection motivation. Social Psychophysiology: $A$ Sourcebook, October 2014, 153-177.

Rohrmann, B. (2008). RISK PERCEPTION, RISK ATTITUDE, RISK COMMUNICATION, RISK MANAGEMENT: A CONCEPTUAL APPRAISAL. Risk Perception, Risk Attitude, Risk Communication, Risk Management: A Conceptual Appraisal, February.

Vijayaraghavan, P., \& SinghalL, D. (2020). A Descriptive Study of Indian General Public's Psychological responses during COVID-19 Pandemic Lockdown Period in India. 1-19. https://doi.org/10.31234/osf.io/jeksn

Yıldırım, M., Geçer, E., \& Akgül, Ö. (2020). The impacts of vulnerability, perceived risk, and fear on preventive behaviours against COVID-19. Psychology, Health and Medicine, 00(00), 1-9. https://doi.org/10.1080/13548506.2020.1776891

Abd Razak, N., Marmaya, N. H., Bte, N. M., Wee, M. F., Arham, A. F., Sa'ari, J. R., ... \& Nordin, N. (2020). Causal Inferences-Risk-Taking Propensity Relationship Towards Entrepreneurial Intention Among Millennials. INTERNATIONAL JOURNAL OF ACADEMIC RESEARCH IN BUSINESS AND SOCIAL SCIENCES, 10(3).

Plotnikoff, R. C., \& Trinh, L. (2010). Protection Motivation Theory: Is This a Worthwhile Theory for Physical Activity Promotion? Exercise \& Sport Sciences Reviews, 38(2), 91-98. https://doi.org/10.1097/JES.0b013e3181d49612

Vijayaraghavan, P., \& SINGHAL, D. (2020). A Descriptive Study of Indian General Public's Psychological responses during COVID-19 Pandemic Lockdown Period in India. https://doi.org/10.31234/osf.io/jeksn 